Article

\title{
How Korean Psychiatric Staff Deal with Religious and Spiritual Issues of Patients: What Is Professional?
}

\author{
Eunmi Lee ${ }^{1,2, *}$ and Klaus Baumann ${ }^{1}$ (1) \\ 1 Caritas Science and Christian Social Work, Faculty of Theology, Albert-Ludwig-University, D-79085 Freiburg, \\ Germany; Klaus.baumann@theol.uni-freiburg.de \\ 2 Center for Social Cohesion, Daegu Catholic University, Hayang-Ro 13-13, Hayang-Eup, Gyeongsan-Si, \\ Gyeongbuk 38430, Korea \\ * Correspondence: eunmi.lee@theol.uni-freiburg.de
}

Received: 19 July 2019; Accepted: 20 September 2019; Published: 22 September 2019

\begin{abstract}
In contrast to other secularized countries, religious and spiritual needs and/or aspects of patient-centred-care are hardly studied in South Korea, even less in the context of psychiatry and psychotherapies. This study investigates religious and spiritual values of Korean psychiatric staff, and their experiences as well as considerations regarding their patients' religious and spiritual aspects in clinical settings. In 2015, we surveyed psychiatric staff in Daegu and suburban areas using Korean versions of the Duke Religion Index and a questionnaire on Religion and Spirituality in Medicine: Physicians' Perspectives by F. Curlin. Six clinics participated in our research. A total of 328 questionnaires were distributed. Ultimately, 270 fully completed questionnaires were analysed (return rate: $82.3 \%$ ). Regarding religious and spiritual values, Korean psychiatric staff does not differ considerably from the average of the Korean population. However, there are significant moderate correlations between their own religious and spiritual attitudes, and their consideration as well as behaviors related to religious and spiritual aspects of their patients. In addition, there is evidence of an unconscious bias which influences treatment. These results call for more professional attention and self-reflective training.
\end{abstract}

Keywords: psychiatry; psychotherapy; religiosity; spirituality; patients' needs; South Korea

\section{Introduction}

Canadian sociologist Charles Taylor (Taylor 2007) asserts we are living in 'a secular age', marked by an increasing elimination of religions from public life in Western societies and their restriction to private life. On the other hand, there are also philosophers like Jürgen Habermas who speaks less of postmodern rather than postsecular societies (Habermas 2005). In fact, Western societies are characterized by a new presence of a multiplicity of religious and spiritual (abbreviated ReS in this further context) groups and phenomena, also due to the many different political challenges like migration, globalization or terrorism. Actually, religions have not disappeared but are present in multiple forms and varieties. ReS needs, attitudes and practices seemingly continue to have considerable roles and impacts in the life of individuals and groups, albeit in new or different forms than in the past regarding their feeling, thinking and acting. It seems that, especially in moments of disease or suffering, people seem to activate or reactivate ReS needs and activities. In fact, religious people search for their God more often and pray more earnestly to cope with their illness. Such ReS needs are quite usual. Therefore, no one considers patients' ReS needs as pathological ones, even in so-called secular societies. Without entering questions concerning the metaphysical truth of ReS beliefs, ReS behavior and subjective experience can become the object of empirical research with its scientific paradigm of epistemological "atheism" (Frick and Baumann 2017). There is an exponentially growing body of research about the 
relationships of religions, spiritualities and health in general (Koenig et al. 2012), also including mental health, psychiatry and psychotherapy (Huguelet and Koenig 2009). This seems less so, however, in East Asia, e.g., South Korea.

The Republic of Korea ("South Korea") is one of the highly industrialized countries, where religious liberties are assured, and the plurality of religions is generally accepted. It is also a country that can be considered strongly secular in Taylor's sense. There is considerable immigration of workers from abroad (about $4 \%$ of the Korean Population) with various religious denominations and a complex presence of various religious groups. According to a Korean nationwide survey in 2015 (Statistics Korea 2016), the percentage of non-believing persons was $56.1 \%$. It was the first time that the atheist or agnostic persons' percentage was higher than the one of believers. Most of the Korean people who confessed a religious denomination were Protestants, Buddhists or Catholics, many of whom are actively engaged in vital religious communities of their respective faiths.

While ReS needs of patients seem very acceptable for practitioners in somatic medicine and especially in life threatening diseases, we wondered about the situation in clinical psychiatry and psychotherapy in Korea. To our knowledge, after consulting academic information systems, e.g., RISS (Research Information Sharing Service), there are no studies in this geographic context with this specific focus. If any study was conducted with this topic, i.e., religion and psychiatry in Korea, then it was focused on religion-related psychotic behaviors such as religious delusion or the relation between specific religions and mental well-being in Koreans who are not diagnosed with any mental disorder. Therefore, we intended to conduct a replication study with the design realized in a German study of staff in clinical psychiatry and psychotherapy (Lee et al. 2011, 2014, 2015). In other words, we wanted to replicate these research questions and hypotheses in the (South) Korean context:

- How religious or spiritual do psychiatric staff (psychiatrists, therapists, nurses, social workers) consider themselves?

- How do they consider the Religiosity and/or Spirituality of patients when they encounter them in their clinical practice, and how do they consider the role of patients' Religiosity and/or Spirituality in their disease and healing processes?

In addition, in both different cultural contexts including more or less 'secularized' societies and in personal attitudes, we hold it necessary to respect that respondents may feel so 'distant' from religious ideas and imaginations (Freud and Meng 1963, pp. 12f) or 'religiously unmusical' (Habermas and Ratzinger 2006); we hold it more adequate to offer a possible response apart, a response to the whole question as such, expressing one's personal distance or overall foreignness from what might be meant by religious or spiritual terms or behaviors in their personal lives. This approach has also resulted in an adaption of the questionnaires used, and its implications will be commented on in the corresponding sections of this article (i.e., Method, Results, and Discussions).

\section{Materials and Methods}

\subsection{Materials}

To explore ReS values of psychiatric staff, we used the Duke University Religion Index (DUREL). This instrument is composed of five questions, which ask about extrinsic (organizational and non-organizational) as well as intrinsic religious characteristics. As a brief measure of religiosity, DUREL has been used in various countries worldwide, and also its psychometric qualities are identified by several studies (Koenig and Büssing 2010; Lee et al. 2011; Storch et al. 2004). Originally, each question about extrinsic religiosity was measured using a 6-point scale., and three questions about intrinsic religiosity were measured according to a 5-point scale, with response options ranging from definitely not true to definitely true of me. Meanwhile, the translated option 'unsure' was separately given in our questionnaire in order to ensure that the nature of the ordinal scale was not affected in the German as well as in the Korean version. Along with cultural differences, the translated word 'unsure' can mean 
either 'I have no idea' or 'I am not sure'. In addition, in our pilot study (Lee et al. 2011), the number of respondents found this term ambiguous, resulting in it being difficult to answer. Therefore, after several discussions with a team of professionals, we decided to offer the option 'unsure' separately, not within the 5-ordinal scale. Ultimately, the three items of intrinsic religiosity in our study showed a good reliability (internal consistency) of $\alpha=0.895$.

In addition, we used a part of a questionnaire on Religion and Spirituality in Medicine: Physicians' Perspectives (RSMPP), developed by Curlin and his team in 2002, to see how psychiatric staff observe ReS aspects of patients in practical settings. The main part of RSMPP is 'Physician Perspectives on Religion/Spirituality and Health' with 50 Items. These original items were constructed based on several relevant literature and qualitative pilot studies, and they were tested via multiple iterations of an expert panel review (Curlin et al. 2007). In recent years, RSMPP has been used to see professionals' aspects on $\mathrm{ReS}$ issues in various medical specialties, such as geriatrics, internal medicine or psychiatry, in several nations (Kørup et al. 2017; Hvidt et al. 2016).

For the first time, we translated these instruments into German and used them. Above all, items were modified to suit psychiatric and psychotherapeutic settings. These were revised by medical professionals and then used first in our pilot study at Freiburg University and then in our nationwide research project in Germany in 2011. Results were published in various peer-reviewed academic journals as well as in the PhD thesis of the first author of this paper (Lee 2014).

Again, to observe ReS characteristics of Korean psychiatric staff and their perspectives related to religiosity and spirituality in clinical settings, we translated the questionnaires from the German version into Korean, checking them with the English version too. For further comparative studies with German psychiatric staff members, not the original English but the modified German version was translated into Korean. A bilingual person (German and Korean) reviewed and improved our translation of these questionnaires two times. The penultimate (pre-final) translated version was checked by two Korean psychiatric professionals once again (Lee and Baumann 2019). In every participating clinic, a clinic committee considered and approved of participating in this study. In accordance with the tenets of the Helsinki declaration, every participant was assured of anonymity and of the freedom to participate or not or to withdraw at any moment without any negative consequence for her or him. No formal approval by another ethics committee was needed because no vulnerable participant groups (e.g., patients) were included.

\subsection{Respondents}

From April to May 2015, an anonymous survey was conducted among Korean staff working in psychiatric departments in Daegu (the fourth biggest city of South Korea, located in the southeastern part of the peninsula) and its suburban areas. We asked each medical director of the clinic via email and telephone for participation in our project. After conferences of each clinic itself, a total of six clinics agreed to participate in this study. Four clinics are located in Daegu, the others respectively in Chilgok and Yeongcheon.

A paper-based questionnaire was distributed to psychiatric staff. A voucher (5000 Won in Korean currency-about 3.80 Euro) was given to each participant who filled out the questionnaire. The survey was anonymously conducted; all potential participants were assured of the strict confidentiality and their right to withdraw at any time. Through personal visits, all questionnaires of each clinic were collected.

\subsection{Statistical Analysis}

All data were analyzed with SPSS 25.0 for Windows (IBM, NY, US). To test the difference between groups and variables, cross-tabulation as well as Pearson's chi-squared-test, Fisher's exact test, $t$-test, univariate analyses of variance (UNIANOVA), in addition to Scheffé's post hoc test and Spearman's rank correlation were used. Significance level was set at $p<0.05$. 
Basically, all responses were tested according to demographic characteristics, incl. sex, occupation, age and religion. Furthermore, the response option 'unsure' was tested separately to check if there were any significant differences. By extension, the scores of an ordinal scale which puts 'unsure' at the center of five answers, in compliance with the original version of DUREL, was supplementarily calculated to see possible differences. No major differences were observed between these two approaches (see Appendix A).

\section{Results}

A total of 328 questionnaires were distributed, and 281 questionnaires were returned (response rate $85.67 \% ; n=281$ of 328 ). Due to incomplete responses, 270 questionnaires could be included in the statistical analysis, resulting in a final response rate of $82.3 \%$.

\subsection{Demographic Characteristics}

On average, the 270 respondents were 34 years old ( $33.79 \pm 9.38$ : youngest 21 -eldest 73$)$. Nearly $70 \%$ were women and most of the participants were nurses (Table 1 ). While slightly more than half the psychiatrists were male, more than $80 \%$ of the nurses as well as the psychotherapists (incl. psychologists) were women. This difference was statistically significant $\left(\chi^{2}=36.231, p<0.001\right)$. More than half the participants were persons without religious affiliation. Among the participants providing religious affiliations, Protestants made up $43.2 \%$. The others were Catholics and Buddhists ( $28.8 \%$ and $27.2 \%$, respectively). Only one person indicated his faith as Daesoon Jinrihoe, one of the Korean new religious movements. Furthermore, according to gender, a significant difference regarding religious affiliation was shown $\left(\chi^{2}=10.334, p=0.001\right)$, i.e., more than $50 \%$ of women have some religious affiliation, while almost $70 \%$ of men have no religious affiliation. Detailed information is described in Table 1.

Table 1. Characteristics of survey respondents.

\begin{tabular}{|c|c|c|}
\hline & Variable & Values $^{1}$ \\
\hline \multicolumn{2}{|c|}{ Absolute number } & $270(100.00)$ \\
\hline \multirow{4}{*}{ Age } & $20-29$ & $115(42.60)$ \\
\hline & $30-39$ & $90(33.30)$ \\
\hline & $40-49$ & $45(16.70)$ \\
\hline & 50 and over & $20(7.40)$ \\
\hline \multirow{2}{*}{ Sex } & Female & $186(68.90)$ \\
\hline & Male & $84(31.10)$ \\
\hline \multirow{5}{*}{ Occupation } & Psychiatrist & $42(15.60)$ \\
\hline & Psychotherapist (incl. & $28(10.40)$ \\
\hline & Nurse & $125(46.30)$ \\
\hline & Social Worker & $67(24.80)$ \\
\hline & Others & $8(3.00)$ \\
\hline \multirow{2}{*}{ Denomination } & No religious affiliation & $144(53.30)$ \\
\hline & Have a religious affiliation & $126(46.70)$ \\
\hline \multirow{6}{*}{ Churchgoing } & More than once a week & $13(4.80)$ \\
\hline & Once a week & $38(14.10)$ \\
\hline & A few times a month & $17(6.30)$ \\
\hline & A few times a year & $34(12.60)$ \\
\hline & Once a year or less & $38(14.10)$ \\
\hline & Never & $130(48.10)$ \\
\hline \multirow{6}{*}{ Private $\operatorname{ReS}$ activities } & More than once a day & $6(2.20)$ \\
\hline & Every day & $24(8.90)$ \\
\hline & More than two times a week & $26(9.60)$ \\
\hline & Once a week & $10(3.70)$ \\
\hline & A few times a month & $16(5.90)$ \\
\hline & Seldom or never & $188(69.60)$ \\
\hline
\end{tabular}

${ }^{1}$ The numbers in brackets refer to the percentage in each category. 


\subsection{Religious and Spiritual Characteristics}

Regardless of religious affiliations, respondents were individually asked if they consider themselves as a (non-)believer. Respondents who proclaimed themselves non-believers were $56.7 \%$. Women considered themselves as believing people significantly more often than men $(p=0.001)$, but there was no significant difference with regard to age. Among four occupational groups (as the number of the group 'others' is not enough for the statistical analysis, this group is in this case deleted), psychiatrists and psychotherapists had significantly more tendencies to express themselves as non-believers than nurses or social workers $(p=0.001)$.

The majority of participants do not participate in any religious or spiritual activities. Namely, about $70 \%$ of respondents hardly ever or never practice religious activities such as Bible reading, meditation, private prayer, etc.; $48 \%$ do not go to churches, temples or similar religious places. Among believing participants, about $40 \%$ go to such ReS places at least once a week. More than half of the believers (privately) practice non-organizational ReS acts more than once a month. However, $40 \%$ answered seldom or never in response to this question, and approximately $15 \%$ never go to churches or religion-related places (shown in Table 1).

Furthermore, participants were asked about their intrinsic religiosity using an ordinal scale from 1 to 4 . Separately, the response option 'unsure' was offered, which is not unequivocal and therefore not between true/not true (cf. Lee et al. 2011, 2014). This separate answer was at first analyzed to see whether there is any remarkable difference between respondents who could choose answers 1 to 4 and who were unsure about these questions. However, according to demographic characteristics, there was no remarkable difference.

The intrinsic religious orientation of psychiatric staff was as follows. The majority of participants replied that religious beliefs usually do not influence their whole approach to life $(m=2.18)$ and that they usually do not make an effort to carry their beliefs into other aspects of life ( $m=2.14)$. More than $40 \%$ state that they definitely do not experience God's presence in their daily life $(m=1.80)$. Detailed information is shown in Table 2.

Table 2. Intrinsic religiosity of psychiatric staff ${ }^{1}$.

\begin{tabular}{|c|c|c|c|c|c|}
\hline & $\begin{array}{l}\text { Definitely } \\
\text { True of Me }\end{array}$ & $\begin{array}{l}\text { Tends to } \\
\text { Be True }\end{array}$ & $\begin{array}{l}\text { Tends Not to } \\
\text { Be True }\end{array}$ & $\begin{array}{l}\text { Definitely } \\
\text { Not True }\end{array}$ & Unsure \\
\hline $\begin{array}{l}\text { Religious beliefs influence whole } \\
\text { approach to life }\end{array}$ & $14(5.20)$ & $80(29.60)$ & $80(29.60)$ & $65(24.10)$ & $31(11.50)$ \\
\hline $\begin{array}{c}\text { Try to carry religion into other } \\
\text { aspects of life }\end{array}$ & $10(3.70)$ & 79 (29.30) & $99(36.70)$ & $64(23.70)$ & $18(6.70)$ \\
\hline Experience God's presence & $6(2.20)$ & 49 (18.10) & $86(31.90)$ & $112(41.50)$ & $17(6.30)$ \\
\hline
\end{tabular}

${ }^{1} n=270$; The numbers in brackets refer to the percentage in each category.

The score of intrinsic religiosity was calculated as the sum of the above three items. Hereby, the highest possible score was 12.0. A total of 229 cases, who responded to all three items, were analyzed. Their intrinsic religiosity was $m=6.13$ (SD = 2.38), which is slightly higher than the median (which is 6.0). Moreover, we compared the scores of intrinsic religiosity concerning the subgroups (age, sex, occupation, denomination, and expression as a believing person), and there is a significant difference according to each subgroup. Further information is described in Table 3.

\subsection{Staff Observations on Religious and Spiritual Aspects among Their Patients}

According to the psychiatric staff's responses, Korean psychiatric patients usually mentioned ReS themes ( $46.3 \%$ sometimes, $38.9 \%$ often). Almost $55 \%$ of respondents answered that their patients occasionally got emotional as well as practical support from religious communities. One fourth of psychiatric staff experienced such emotional relief from their patients often or always. In addition, more than $40 \%$ of staff did not observe that patients reject their responsibilities for their own mental 
health because of any religious reasons, while $43 \%$ observed such rejection sometimes and $16 \%$ even often. Mean results are described in Table 4.

Table 3. Intrinsic religiosity between subgroups.

\begin{tabular}{cccc}
\hline Variable & M (SD) ${ }^{\mathbf{1}}$ & $\mathbf{F}$ & Sig. \\
\hline Intrinsic religiosity & $6.13( \pm 2.38)$ & & \\
\hline Age (years) & & 5.241 & $p=0.002$ \\
$20-29$ & $5.66( \pm 2.20)$ & & \\
$30-39$ & $6.18( \pm 2.44)$ & & \\
$40-49$ & $6.29( \pm 2.30)$ & & \\
50 and over & $8.06( \pm 2.41)$ & & \\
Sex & & 6.563 & \\
Female & $6.41( \pm 2.33)$ & & \\
Male & $5.56( \pm 2.40)$ & & \\
Occupation & & 3.134 & \\
Psychiatrist & $5.23( \pm 2.28)$ & & \\
Nurse & $5.39( \pm 2.17)$ & & \\
Social Worker & $6.32( \pm 2.32)$ & & \\
Others & $6.63( \pm 2.49)$ & & \\
Psychotherapist (incl. psychologist) & $7.40( \pm 2.51)$ & & \\
Denomination & & 164.265 & \\
No religious affiliation & $4.69( \pm 1.54)$ & & \\
Have a religious affiliation & $7.78( \pm 2.10)$ & & \\
Confession & & 220.932 & $p<0.001$ \\
as a non-believer & $4.69( \pm 1.55)$ & & \\
as a believer & $8.06( \pm 1.89)$ & & \\
\hline INumeric restts were & & \\
\hline
\end{tabular}

${ }^{1}$ Numeric results were rounded up to the nearest hundredth.

Table 4. Experiences with religious and spiritual aspects of patients from RSMPP.

\begin{tabular}{|c|c|c|}
\hline \multirow{2}{*}{ Questionnaire Items $^{1}$} & \multicolumn{2}{|r|}{ Analysis } \\
\hline & Mean $^{2}$ & Correlation with Intrinsic Religiosity ${ }^{3,4}$ \\
\hline Patients mentioned ReS issues such as God, prayer, meditation, the Bible, etc. & $3.23 \pm 0.82$ & 0.01 \\
\hline ReS helps patients to cope with and endure illness. & $3.02 \pm 0.76$ & $0.27 * *$ \\
\hline ReS leads patients to refuse, delay, or stop medically indicated therapy. & $3.00 \pm 0.83$ & $-0.16^{* *}$ \\
\hline ReS gives patients a positive, hopeful state of mind. & $3.06 \pm 0.76$ & $0.33^{* *}$ \\
\hline ReS helps patients to prevent "hard" medical outcomes like death via suicide. & $2.87 \pm 0.77$ & $0.33^{* *}$ \\
\hline Patients used $\operatorname{ReS}$ as a reason to avoid taking responsibility for their own health. & $2.71 \pm 0.84$ & $-0.19 * *$ \\
\hline Suffering from an illness often leads patients to ReS. ${ }^{5}$ & $2.81 \pm 0.90$ & 0.09 \\
\hline
\end{tabular}

${ }^{1}$ Preceded by "considering your experience ... " ${ }^{2}$ Response categories are: $1=$ never, 2 = rarely, $3=$ sometimes, $4=$ often, $5=$ always. ${ }^{3}$ Correlation between the sum of staff' own intrinsic religiosity scores and their response to the items. ${ }^{4}$ Spearman's correlation (1-tailed): ${ }^{* *} p<0.01,{ }^{*} p<0.05 .{ }^{5}$ In the original questionnaire, this item asked whether "religiosity/spirituality causes guilt, anxiety, or other negative emotions that lead to increased patient suffering". Based on comments from the respondents of the pilot study and other comments from a professional team, this question was replaced by the item "Suffering from an illness often leads patients to religiosity/spirituality".

\subsection{Relations with Personal Religious Values}

Is there a (cor-) relation between psychiatric staff's personal ReS values on the one hand and how they experience the impacts of religions or related aspects on patients' mental health on the other hand? We analyzed the correlation between participants' intrinsic religiosity and relevant items of patient-related experiences in RSMPP. The results show that psychiatric staff's own intrinsic religiosity is moderately to highly significantly correlated with how they experienced ReS aspects of patients in practical settings. In other words, they observed ReS influences on patients as well as their mental 
health more positively when religions or such beliefs are important for staff themselves. For instance, the more staff themselves are religious, the more often they observe that religions influence patients' mental health positively in general $(r=0.32, p<0.01)$; they also experienced that psychiatric patients got hopeful and affirmative in their mental status through their faiths $(r=0.33, p<0.01)$. More correlations are reported in Table 4.

\section{Discussion}

With our results, we can give a first response to our question: How ReS do psychiatric staff consider themselves?

First, 56.7\% answered that they are not believers. In a comparison with the numbers of the Korean non-believers (56.1\%) according to a nationwide survey in 2015, there is no big difference. Generally speaking, according to our data, Korean psychiatric staff usually engage neither in organizational nor in non-organizational ReS acts. This is true even for believing persons. In contrast, according to a survey of Gallup Korea (2014), among believers, $44 \%$ claimed to go to a church, temple or similar places more than once a week. On the other hand, 3 of 10 persons on average go to such ReS places once a year at most or never. In comparison with German data, the percentage shows a distinct difference. In a German nationwide study of 2011 , about $60 \%$ of psychiatric staff considered themselves believing persons. Among psychiatrists, more than $55 \%$ responded that they have a faith. Furthermore, the Korean psychiatric staff generally do not connect ReS aspects into their daily lives. The sum of the intrinsic religiosity was $m=6.13$, while, in the German study, the mean value was 7.01. A mean score of 6 (between 3 and 12) means that, as to items of intrinsic religiosity, the 'mean' response would be 'tends to be not true'. Even if the separately offered response 'unsure' is put into the middle of an ordinal scale between 'true of me/not true' for (secondary) statistical purposes, thus including all 270 respondents, the results do not differ remarkably $(\mathrm{M}=7.23, \mathrm{SD}= \pm 3.31$, of a scale between 3 and 15; see Appendix A).

Interestingly, in the Survey of Gallup Korea (2014), about 52\% of Koreans considered religions somewhat or very important in their lives, while about $48 \%$ answered rather not or even not at all meaningful. In this context, it seems that ReS issues are not noticeably less important for psychiatric professionals than for the Korean population in general. Further research and statistical comparisons need to explore, more specifically, if Korean psychiatric staff are less ReS than the Korean population in general or not and if there are meaningful subgroups that differ, e.g., according to religious denominations.

Secondly, we obtained valuable information about the question: How do they consider the Religiosity and/or Spirituality of patients, by extension, the role of patients' Religiosity and/or Spirituality in their disease and healing process?

More than $80 \%$ of Korean psychiatric professionals stated that patients sometimes or even often mentioned ReS issues Occasionally, psychiatric staff observed that patients got supports, such as psychological stabilities or social support network, from the same ReS groups, and they could become more peaceful through ReS resources. In other words, health professionals confirmed that religiosity and/or spirituality can play a role as a positive coping resource (cf. Pargament et al. 2005). However, together with this finding, our study also figured out that Korean psychiatric staff hardly regard ReS aspects as coping resources. It seems they still follow the mainstream legacy of Freud's psychoanalysis which compared religions to obsessive-compulsive neuroses (Freud 1907, 1927; cf. Baumann 2007, 2012). They do not consider such ReS factors to be integrated into therapeutic processes. Many of the participants commented that religions as well as related issues should not be handled in clinical settings, as religions and such issues are just private; in addition, they commented that they encountered ReS phenomena in pathological contexts, such as religious delusions, from time to time.

These remarks of practitioners in mental health seem self-contradictory. For example, one psychiatrist mentioned, "I wonder with what kind of intention you do such a survey. I hope, please, there is 
not any intention to integrate religion into psychiatry." He added that religion could also be just unhealthy, and absolutely it should not be handled in psychiatric settings. While, based on our suspicion, there is a general refusal suspecting our research intentions in this remark, the second part is inconclusive and even self-contradictory: if religion can be "just unhealthy" for patients, why should it not be dealt with, even "absolutely" not, in psychiatric settings? If a patient's religiosity is unhealthy and thus part of the patient's psychopathology, it needs to be dealt with appropriately and professionally rather than be neglected (cf. Huguelet and Koenig 2009).

Third, and also in consequence of the previous finding, we have to take note of the significant relations between psychiatric staff's own intrinsic religiosity and their attitudes to patients' religions-related aspects. There is a bias in mental health professionals which influences their dealing with patients and their ReS needs. According to our results, more highly ReS staff members pay more attention to ReS aspects of patients; in addition, they consider influences of ReS aspects more positively. The same is true vice versa: the less psychiatric staff is spiritually oriented, the more they tend to neglect ReS needs of their patients, and the more they tend to consider ReS aspects of their patients negatively.

Not only in our current survey, but also in other studies (Lee and Baumann 2013; Lee et al. 2011), professional neutrality is the strongest reason why psychiatric staff members say they will not deal with religions and related aspects in clinical settings. Our results give proof that clinicians are not neutral; significant moderate correlation shows that health professionals differ (unconsciously) according to their attitudes. The previously mentioned comment of a psychiatrist provides a lively illustration of this situation. This situation calls for improvement: we need to aim at transparent and reflected value-openness instead of (unrealistic) value-neutrality (Bergin et al. 1996). If ReS and other ethical issues are treated differently depending on health professionals' personal values, professionals should come to grips with their values and biases related with specific issues such as religions in a reflective, transparent and balanced way. Neglecting them can never be a professional solution. Rather, they call for more professional attention and self-reflective training. This has become even more important in "secular ages" and "post-secular societies", which are characterized by a new presence of a multiplicity of ReS groups and phenomena. Actually, ReS needs, attitudes and practices continue to have considerable roles and impacts in the life of individuals and groups, albeit in new or different forms than in the past regarding their feeling, thinking and acting. In moments of disease or suffering, many people seem to activate or reactivate ReS needs and activities. It is part of psychiatric professional ethics (cf. Reiser 2018) and ought to be part of professional practice that patients' various dimensions and socio-cultural backgrounds are respected, including ReS like other personal attributes e.g., political views, sexual attitudes, or even private hobbies. Furthermore, personal attributes like gender, race, political views and religious orientations do affect psychiatric professional members in patients-staff's clinical relationships (Cook 2011).

\section{Conclusions}

In medicine and other health related sciences, there is an academic prevalence of a secular scientific paradigm which understands its epistemology as empirical and functionally atheistic. At the same time, health practitioners (physicians as well as nurses or other therapists) meet patients and their relatives, not only as bearers of syndromes but also as persons in the totality of their bodily, mental and social lives, including ReS dimensions. The patients and their relatives do so vice versa in meeting the health professionals.

In medicine and all health professions, therefore, the importance of holistic patient-centered care ought to be standard. In recent decades, bio-psycho-social dimensions have increasingly gained attention. Along with these, patients' ReS needs should also be perceived and emphasized. The WHOQOL explicitly considers ReS and personal beliefs as relevant aspects of the quality of life of any individual (WHOQOL SRPB Group 2006). These aspects presumably also influence the feelings, cognitions, behaviors and practices of all persons who interact in the health system. 
We are aware that our study has several limitations, which are considered along with the survey's findings as well as discussions. First of all, this study was done in Daegu and its surroundings only. Therefore, the results are not representative of all Korean psychiatric professionals' attitudes. Studies in other parts of Korea should follow. In addition, the questionnaire used in Korea was a translated version. Therefore, some linguistic differences might have occurred, even though all items used were at the end compared between English, German and Korean, whereupon no one revealed any difficulty with understanding items. More generally, however, we want to raise the issue once more if it is interculturally appropriate to put 'unsure/I don't know' at the center of the ordinal scale in DUREL which is used to measure items of what we call intrinsic religiosity. In our understanding, the expression 'unsure/I don't know' is not unequivocal interculturally and phenomenologically, as exemplified by Batson's (Batson 1976; Batson and Raynor-Prince 1983) category of 'Quest orientation' on one side, and authors like Freud and Habermas on the other side who express their utmost distance to the "ReS world" in various ways.

In addition, we assume that quantitative questionnaires do not reach the same depth of understanding like qualitative in-depth-interviews, which, however, have their own shortcomings. In addition, this paper cannot discuss the possible impact of ReS aspects on patient psychopathology and on patient attitudes towards mental health professionals.

Finally, therefore, we underline the importance of studies dealing with ReS issues, particularly with professionals. In recent years, such themes have been increasingly researched. However, health care workers' religious and other ethical values, their effects on medical practice and health care, as well as their interactions with patients and their families, have only been studied most recently. We are still at an early stage, esp. in psychiatry and psychotherapies on the one hand and in South Korea on the other hand. It is encouraging, however, that, even before finding significant results, a questionnaire itself can give professionals opportunities to think about religions and related professional behaviors. We therefore conclude with adding two quotations that one psychiatrist and one social worker appended to the end of our questionnaire: "Through filling out the questionnaire I got a chance to think about religious effects on therapies with patients, so I am wondering what kind of relations/influences [religions have].", "It let me think about religious influences on taking care of patients. I want to know how big their relations/effects are."

Author Contributions: Both authors conceived of the survey. E.L. has conducted the survey in Korea and calculated the statistics, both authors wrote the text of the paper in all its drafts.

Funding: In the final part, this paper was supported by the National Research Foundation of Korea Grant funded by the Korean Government [2016S1A3A2924944]. For the rest, the paper was funded by the resources of the department of Caritas Science and Christian Social Work at Freiburg University.

Acknowledgments: We are sincerely thankful to Junghan Park (Daegu Catholic University Hospital) who conscientiously reviewed the translated questionnaire and supported a successful contact with psychiatric clinics. We also thank all the clinics and their staff who supported our research by their valuable participation.

Conflicts of Interest: The authors declare no conflict of interest. 


\section{Appendix A}

Table A1. Comparison between intrinsic religiosity scores using a 4-ordinal scale and 5-ordinal scale.

\begin{tabular}{|c|c|c|c|c|c|c|}
\hline \multirow{2}{*}{ Variable } & \multicolumn{3}{|c|}{ Using 4-Ordinal Scale $(n=229)$} & \multicolumn{3}{|c|}{ Using 5-Ordinal Scale $(n=270)$} \\
\hline & M (SD) & $\mathbf{F}$ & Sig. & M (SD) & F & Sig. \\
\hline Intrinsic religiosity & $6.13( \pm 2.38)$ & & & $7.23( \pm 3.31)$ & & \\
\hline Age (years) & & 5.241 & $p=0.002$ & & 4.795 & $p=0.003$ \\
\hline 20-29 & $5.66( \pm 2.20)$ & & & $6.70( \pm 2.98)$ & & \\
\hline $30-39$ & $6.18( \pm 2.44)$ & & & $7.30( \pm 3.43)$ & & \\
\hline 40-49 & $6.29( \pm 2.30)$ & & & $7.36( \pm 3.38)$ & & \\
\hline 50 and over & $8.06( \pm 2.41)$ & & & $9.65( \pm 3.51)$ & & \\
\hline Sex & & 6.563 & $p=0.011$ & & 6.385 & $p=0.012$ \\
\hline Female & $6.41( \pm 2.33)$ & & & $7.56( \pm 3.24)$ & & \\
\hline Male & $5.56( \pm 2.40)$ & & & $6.48( \pm 3.36)$ & & \\
\hline Occupation & & 3.134 & $p=0.016$ & & 3.250 & $p=0.013$ \\
\hline Psychiatrist & $5.23( \pm 2.28)$ & & & $5.98( \pm 3.25)$ & & \\
\hline $\begin{array}{l}\text { Psychotherapist (incl. } \\
\text { psychologist) }\end{array}$ & $5.39( \pm 2.17)$ & & & $6.32( \pm 2.99)$ & & \\
\hline Nurse & $6.32( \pm 2.32)$ & & & $7.39( \pm 3.29)$ & & \\
\hline Social Worker & $6.63( \pm 2.49)$ & & & $7.93( \pm 3.30)$ & & \\
\hline Others & $7.40( \pm 2.51)$ & & & $8.50( \pm 3.21)$ & & \\
\hline Denomination & & 164.256 & $p<0.001$ & & 157.255 & $p<0.001$ \\
\hline No religious affiliation & $4.69( \pm 1.54)$ & & & $5.35( \pm 2.10)$ & & \\
\hline $\begin{array}{c}\text { Have a religious } \\
\text { affiliation }\end{array}$ & $7.78( \pm 2.10)$ & & & $9.37( \pm 3.13)$ & & \\
\hline Confession & & 220.932 & $p<0.001$ & & 248.680 & $p<0.001$ \\
\hline as a non-believer & $4.69( \pm 1.55)$ & & & $5.22( \pm 2.02)$ & & \\
\hline as a believer & $8.06( \pm 1.89)$ & & & $9.85( \pm 2.80)$ & & \\
\hline
\end{tabular}

\section{References}

Batson, C. Daniel. 1976. Religion as Prosocial: Agent or Double Agent? Journal of the Scientific Study of Religion 15: 29-45. [CrossRef]

Batson, C. Daniel, and Lynn Raynor-Prince. 1983. Religious Orientation and Complexity of Thought about Existential Concerns. Journal for the Scientific Study of Religion 22: 38-50. [CrossRef]

Baumann, Klaus. 2007. Zwangsstörung und Religion aus heutiger Sicht. Obsessive-Compulsive Disorders and Religion in Contemporary Perspective. Fortschritte der Neurologie Psychiatrie 75: 587-92. [CrossRef] [PubMed]

Baumann, Klaus. 2012. Remarks on Religions and Psychiatry/Psychotherapies. In Spiritualität und Gesundheit. Spirituality and Health. Ausgewählte Beiträge im Spannungsfeld zwischen Forschung und Praxis. Selected Contributions on Conflicting Priorities in Research and Practice. Edited by René Hefti and Jacqueline Bee. Bern: Peter Lang AG, pp. 99-118.

Bergin, Allen E., Payne I. Reedand, and Richards P. Scott. 1996. Values in Psychotherapy. In Religion and Clinical Practice of Psychology. Edited by Edward P. Shafranske. Washington, DC: American Psychological Association, pp. 297-325.

Cook, Christopher C. H. 2011. The faith of the psychiatrist. Mental Health, Religion and Culture 14: 9-17. [CrossRef] Curlin, Farr A., Ryan E. Lawerence, Shaun Odell, Marshall H. Chin, John D. Lantos, Harold G. Koenig, and Keith G. Meador. 2007. Religion, spirituality, and medicine: Psychiatrists' and other physicians' differing observations, interpretations, and clinical approaches. American Journal of Psychiatry 164: 1825-31. [CrossRef] [PubMed] 
Freud, Sigmund. 1907. Obsessive Actions and Religious Practices. In The Standard Edition of the Complete Psychological Works of Sigmund Freud, vol. IX. Edited by James Strachey. London: Hogarth Press, pp. 117-27.

Freud, Sigmund. 1927. The Future of an Illusion. In The Standard Edition of the Complete Psychological Works of Sigmund Freud, vol. XXI. Edited by James Strachey. London: Hogarth Press, pp. 5-56.

Freud, Ernst L., and Heinrich Meng, eds. 1963. Sigmund Freud-Oskar Pfister: Briefe 1909-1939. Frankfurt: Fischer. Frick, Eckhard, and Klaus Baumann. 2017. Spiritualität-Bedürfnis und Begehren. Empirische Forschung und theologisch-philosophische Reflexion können voneinander lernen. In Religionssensibilität in der Sozialen Arbeit: Positionen, Theorien, Praxisfelder. Edited by Matthias Nauerth, Kathrin Hahn, Michael Tüllmann and Sylke Kösterke. Stuttgart: Kohlhammer, pp. 227-45.

Gallup Korea. 2014. Available online: http://www.gallup.co.kr (accessed on 1 July 2019).

Habermas, Jürgen. 2005. Zwischen Naturalismus und Religion. Philosophische Aufsätze. Frankfurt am Main: Suhrkamp.

Habermas, Jürgen, and Joseph Ratzinger. 2006. The Dialectics of Secularization. On Reason and Religion. San Francisco: Ignatius Press.

Huguelet, Philippe, and Harold G. Koenig. 2009. Religion and Spirituality in Psychiatry. Cambridge: Cambridge University Press.

Hvidt, Niels Christian, Alex Kappel Kørup, Farr A. Curlin, Klaus Baumann, Eckhard Frick, Jens Søndergaard, Jesper Bo Nielsen, René DePont Christensen, Ryan Lawrence, Giancarlo Lucchetti, and et al. 2016. The NERSH International Collaboration on Values, Spirituality and Religion in Medicine: Development of Questionnaire, Description of Data Pool, and Overview of Pool Publications. Religions 7: 107. [CrossRef]

Koenig, Harold G., and Arndt Büssing. 2010. The Duke University Religion Index (DUREL): A Five-Item Measure for Use in Epidemological Studies. Religions 1: 78-85. [CrossRef]

Koenig, Harold G., Dana King, and Verna B. Carson. 2012. Handbook of Religion and Health, 2nd ed. Oxford: Oxford University Press.

Kørup, Alex Kappel, René Depont Christensen, Connie Thurøe Nielsen, Jens Søndergaard, Nada A. Alyousefi, Giancarlo Lucchetti, Klaus Baumann, Eunmi Lee, Azimatul Karimah, Parameshwaran Ramakrishnan, and et al. 2017. The International NERSH Data Pool-A Methodological Description of a Data Pool of Religious and Spiritual Values of Health Professionals from Six Continents. Religions 8: 24. [CrossRef]

Lee, Eunmi. 2014. Religiosität bzw. Spiritualität in Psychiatrie und Psychotherapie. Ihre Bedeutung für psychiatrisches Wirken aus der Sicht des psychiatrischen Personals anhand einer bundesweiten Personalbefragung. Würzburg: Echter Verlag.

Lee, Eunmi, and Klaus Baumann. 2013. German psychiatrists' Observation and Interpretation of Religiosity/Spirituality. Evidence-Based Complementary and Alternative Medicine 2013: 1-8. [CrossRef] [PubMed]

Lee, Eunmi, and Klaus Baumann. 2019. Religiosity and Spirituality: Is It an Appropriate Issue in Psychiatry and Psychotherapy? Comparative Studies of Germany and South Korea. Open Journal of Social Sciences 7: 300-10. [CrossRef]

Lee, Eunmi, Anne Zahn, and Klaus Baumann. 2011. “Religion in Psychiatry and Psychotherapy?” A Pilot Study: The Meaning of Religiosity/Spirituality from Staff's Perspective in Psychiatry and Psychotherapy. Religions 2: 525-35. [CrossRef]

Lee, Eunmi, Anne Zahn, and Klaus Baumann. 2014. Religiosity/Spirituality and Mental Health: Psychiatric Staff's Attitudes and Behaviors. Open Journal of Social Sciences 2: 7-13. [CrossRef]

Lee, Eunmi, Anne Zahn, and Klaus Baumann. 2015. How do Psychiatric Staff's Approach Religiosity/Spirituality in Clinical Practice? Differing Perceptions among Psychiatric Staff Members and Clinical Chaplains. Religions 6: 930-47. [CrossRef]

Pargament, Kenneth I., Gene G. Ano, and Amy B. Wachholtz. 2005. The religious dimension of coping. In Handbook of the Psychology of Religion and Spirituality. Edited by Raymond F. Paloutzian and Crystal L. Park. New York: Guilford, pp. 479-95.

Reiser, Franz. 2018. Menschen mehr gerecht werden. In Zur Religiosität bzw. Spritualität von Patientinnen und Patienten in Psychitarie and Psychotherapie. Würzburg: Echter. 
Statistics Korea. 2016. Available online: http://kostat.go.kr (accessed on 1 July 2019).

Storch, Eric A., Jonathan W. Roberti, Amanda D. Heidgerken, Jason B. Storch, Adam B. Lewin, Erin M. Killiany, Audrey L. Baumeister, Erica A. Bravata, and Gary R. Geffken. 2004. The Duke Religion Index: A Psychometric Investigation. Pastoral Psychology 53: 175-81. [CrossRef]

Taylor, Charles. 2007. A Secular Age. Cambridge: Harvard University Press.

WHOQOL SRPB Group. 2006. A cross-cultural study of spirituality, religion, and personal beliefs as components of quality of life. Social Science $\mathcal{E}$ Medicine 62: 1486-97. [CrossRef] 